\title{
Introduction to the special issue: A tribute to Pietro Torasso
}

\author{
Piero's Scholars and Colleagues
}

This special issue is a tribute to Pietro (Piero) Torasso, who suddenly left us on Christmas day, 2016. Piero was a role model and leader for Artificial Intelligence in Italy and worldwide. He was one of the founders of the AI school in Torino; he was in the group who established AI*IA, the Italian AI Association in the 80's; he was a fellow of ECCAI, the European AI Association. Piero moved across different areas of Artificial Intelligence and the papers that follow will review some of these contributions. There are, however, some aspects of Piero's profile that cannot emerge from these kinds of papers.

Piero had incredibly deep knowledge and a broad view of Artificial Intelligence. You could discuss with him nearly any topic and receive interesting comments, insights. At the same time he always had the general picture in mind and could put the discussion within this picture.

Piero was extremely rigorous in his behavior and his work. For many years he has been the chair of the Computer Science Department and then the coordinator of the Computer science and $\mathrm{PhD}$ schools in Torino; all colleagues and students experienced his ability in managing technical and administrative issues. In doing this Piero was an incredible data analyzer. He used to prepare before any meeting by analysing data and then supporting his position with evidence from data. His interventions during meetings were always interesting and full of insights and everybody, even with very different points of view and positions, always paid attention to them.

Piero was an enthusiastic teacher. Beginning with the course "Elaborazione dell'informazione non numerica" in 1978, regarding the foundations of AI at that time, he has always taught $\mathrm{AI}$ courses at the University of Torino, by continuously updating their contents according to the evolution of the various areas of AI. Recently, he was teaching two courses: one on "Intelligent Systems" for the "laurea triennale" on Computer Science and an advanced one on "AI and laboratory" for the "laurea magistrale". Many generations of students in Torino attended his course on the foundations of Artificial Intelligence which they found interesting and stimulating. Piero tutored a large number of licence and doctoral dissertations, and helped several young researchers in their first steps in the research world. In his relationships with these young people, he succeeded in stimulating their curiosity for the discovery, the dedication to the tasks, and the intellectual honesty that characterised himself. Most of them carried on these experiences to their professions. Many of them still work on AI-related topics in academia, research centers and companies. Piero grew generations of researchers. Most of them worked with Piero for a few years and then moved to create their own research profile and group, still maintaining relationships with Piero who was always available for them to discuss research issues, to provide feedback and suggestions.

Among Piero's numerous activities, we want to mention the technological transfer toward industries and public entities. Piero participated to (or directed) a great number of joint projects of applied research, both at the national and the international level, thus contributing to the diffusion of the research results in various sectors of industry and society.

In this special issue we describe Piero's contribution to AI research in five chapters: (i) the work on 
approximate reasoning, (ii) the work on natural language processing, (iii) the long path on diagnostic problem solving with (iv) significant contributions to case based reasoning, (v) the work on adaptive systems. Although we know that this is not a complete picture, we believe that it can provide an overview of Piero's broad contribution to AI.
Luca Anselma, Liliana Ardissono, Luca Console, Barbara Di Eugenio, Anna Goy, Vincenzo Lombardo, Diego Magro, Alberto Martelli, Roberto Micalizio, Giovanna Petrone, Luigi Portinale, Lorenza Saitta, Enrico Scala, Marino Segnan, Paolo Terenziani, Daniele Theseider Dupré, Gianluca Torta. 